\title{
Sensitivity of Botrytis cinerea to fungicides used in New Zealand wine grape spray programmes
}

\author{
R.M. Beresford ${ }^{1}$, P.J. Wright ${ }^{2}$, C.L. Middleditch ${ }^{1}$, M. Vergara ${ }^{1}$, L. Hasna ${ }^{1}$, P.N. Wood $^{3}$ and \\ R.H. Agnew ${ }^{4}$ \\ ${ }^{1}$ The New Zealand Institute for Plant \& Food Research Ltd, Mt Albert Research Centre, \\ Private Bag 92169, Auckland 1142, New Zealand \\ ${ }^{2}$ The New Zealand Institute for Plant \& Food Research Limited, Pukekohe Research Centre, \\ Cronin Road, RD1 Pukekohe, New Zealand \\ ${ }^{3}$ The New Zealand Institute for Plant \& Food Research Ltd, Hawke's Bay Research Centre, \\ Private Bag 1401, Havelock North, Hastings 4157, New Zealand \\ ${ }^{4}$ The New Zealand Institute for Plant \& Food Research Ltd, Marlborough Wine Research \\ Centre, PO Box 845, Blenheim 7240, New Zealand \\ Corresponding author: robert.beresford@plantandfood.co.nz
}

\begin{abstract}
Fungicide resistance development in Botrytis cinerea threatens the efficacy of anilinopyrimidine (AP) fungicides, which have been used for botrytis bunch rot control in New Zealand vineyards for about 20 years. A 2016 survey of 33 vineyards in Gisborne, Hawke's Bay and Marlborough showed that the majority of 670 isolates tested in agar-based assays were sensitive to the AP cyprodinil $\left(\mathrm{EC}_{50}<1 \mathrm{mg} /\right.$ litre), although $18 \%$ showed low-resistance $\left(\mathrm{EC}_{50} 1-10 \mathrm{mg} / \mathrm{litre}\right)$ and $10 \%$ showed medium-resistance $\left(\mathrm{EC}_{50}>10 \mathrm{mg} / \mathrm{litre}\right)$. There was high cross-resistance to the APs cyprodinil and pyrimethanil. The survey also established baseline sensitivity to the succinate dehydrogenase inhibitor (SDHI) fungicide boscalid and $>90 \%$ of isolates were sensitive $\left(\mathrm{EC}_{50}<5 \mathrm{mg} /\right.$ litre). There was a low degree of cross-resistance between the SDHIs boscalid and fluopyram. There was also high sensitivity to fludioxonil (0.009 to $0.018 \mathrm{mg} /$ litre) and to fenhexamid (0.49 to $0.76 \mathrm{mg} /$ litre) .
\end{abstract}

Keywords Botrytis bunch rot, fungicide resistance management, cross-resistance.

\section{INTRODUCTION}

Fungicides are relied on for control of Botrytis cinerea (botrytis bunch rot) in wine grapes, but this pathogen has a high propensity to develop resistance to fungicide groups that have site-specific modes of action. In New Zealand, resistance development halted the use of benzimidazoles and greatly reduced the use of dicarboximides for botrytis bunch rot control during the 1980s (Beever et al. 1989). Resistance has also developed internationally to the anilinopyrimidine (AP) group (Walker et al. 2013). The AP group was first introduced into New Zealand in the late 1990s. Since then, the two active ingredients, pyrimethanil and cyprodinil, have become the mainstay of vineyard control of botrytis bunch rot. They have always been used under a resistance management strategy (Beresford et al. 1999) but the strategy was tightened in 2014 (Beresford et al. 2014) in response to concerns about the high reliance on 
APs. However, these changes were made without survey data indicating whether resistance was actually developing.

Another group of fungicides is succinate dehydrogenase inhibitors (SDHI) that inhibit fungal respiration at the ubiquinone binding site of the SDH enzyme. This group contains fungicides that are effective against both B. cinerea and Erysiphe necator (grapevine powdery mildew). Resistance to SDHI fungicides is well known overseas in B. cinerea (Sierotzki \& Scalliet 2013), but has not been found in E. necator (FRAC 2015). Products containing SDHIs have been used in grapes in New Zealand since about 2008, and both the SDHI products currently registered for grapes contain a mixture of an SDHI and a quinone outside inhibitor (QoI) fungicide. One of those products, Pristine $^{\circledR}$, contains boscalid plus pyraclostrobin and has a label claim for both botrytis and powdery mildew. The other, Luna ${ }^{\circledR}$ Sensation, contains fluopyram plus trifloxystrobin and has a claim only for powdery mildew. There is the risk of SDHI resistance selection in B. cinerea from the use of either of these products. Therefore, knowledge of $B$. cinerea SDHI sensitivity in New Zealand vineyards is essential so that any need to review the current resistance management strategy (Beresford et al. 2011) can be identified.

This study sought to obtain field data on the sensitivity of $B$. cinerea to key fungicides to inform the development of resistance management strategies for wine grapes in New Zealand. The objectives were to: 1 ) survey $B$. cinerea nationally to determine sensitivity to the AP and SDHI active ingredients (cyprodinil and boscalid, respectively), 2) investigate selected $B$. cinerea phenotypes from the national survey for crossresistance to other active ingredients within the AP (pyrimethanil) and SDHI (fluopyram) groups and 3 ) investigate other at-risk fungicides used in wine-grape spray programmes - specifically fludioxonil, which is the mixing partner in cyprodinil-containing products and fenhexamid, which has been in use in New Zealand vineyards for about 15 years.

\section{MATERIALS AND METHODS \\ Collection of Botrytis cinerea isolates and spray diary data}

For the national survey, single spore isolates of $B$. cinerea were obtained from 33 vineyard blocks in Gisborne (11 Chardonnay blocks), Hawke’s Bay (10 Sauvignon blanc blocks) and Marlborough (12 Sauvignon blanc blocks) in March and April 2016. Twenty to 25 isolates were obtained from each block and a total of 670 isolates were available for testing. Blocks were chosen to represent a geographical spread within each region and organic vineyards were sampled for one block in Gisborne, two in Hawke's Bay and two in Marlborough. Vineyard managers were asked to provide spray diary information through a questionnaire on their use of resistance-risk fungicides. This queried numbers of applications per season for each of the last five seasons (2011-12 to 2015-16), and the average number per season for the previous 10 seasons (2001-2 to 2010-11). Nine active ingredients were surveyed: cyprodinil and fludioxonil in mixture, pyrimethanil, boscalid (mixed with pyraclostrobin), fenhexamid, fluazinam, iprodione, procymidone and carbendazim.

\section{Fungicide sensitivity testing}

Six fungicides were tested for sensitivity (Table 1). For testing AP fungicides (cyprodinil and pyrimethanil), the modified GGA medium of Milling \& Richardson (1995) was used, which contained: $15 \mathrm{~g}$ agar, $0.4 \mathrm{~g} \mathrm{MgSO}_{4} .7 \mathrm{H}_{2} 0,1.8 \mathrm{~g}$ $\mathrm{KH}_{2} \mathrm{PO}_{4}, 4 \mathrm{~g}$ glucose, $4 \mathrm{~g}$ gelatin and 1 litre water. For SDHI fungicides (boscalid and fluopyram), a succinate medium recipe supplied by Bayer CropScience was adapted, which contained: $12 \mathrm{~g}$ agar, $0.75 \mathrm{MgSO}_{4} .7 \mathrm{H}_{2} 0,2.4 \mathrm{~g} \mathrm{~K}_{2} \mathrm{HPO}_{4}, 3.2 \mathrm{~g} \mathrm{KH}_{2} \mathrm{PO}_{4}$, $1.2 \mathrm{~g}\left(\mathrm{NH}_{4}\right)_{2} \mathrm{SO}_{4}, 6 \mathrm{~g}$ sodium succinate dibasic hexahydrate, $2.4 \mathrm{~g}$ yeast extract and 1 litre water. The two other fungicides (fludioxonil and fenhexamid) were tested on potato dextrose agar. Fungicide sensitivity of each $B$. cinerea isolate was determined from colony diameters after 3 days' growth on agar in $9-\mathrm{cm}$ vented Petri plates at each fungicide concentration. Two replicate plates were used per isolate and two colony diameter measurements were made at right angles for each replicate. 
All the fungicides tested were commercial formulations supplied by the manufacturers (Table 1). The national survey isolates were tested on two discriminatory doses and a control of the AP fungicide cyprodinil (0,1 and $10 \mathrm{mg} /$ litre) and the SDHI fungicide boscalid (0, 5 and $50 \mathrm{mg} /$ litre). To examine cross-resistance within the AP group, cyprodinil and pyrimethanil were tested at $0,0.1,0.5,1,5,10$ and $50 \mathrm{mg} /$ litre on 30 isolates (the 15 most cyprodinil-sensitive and the 15 most cyprodinil-resistant from the national survey). Similarly, for the SDHI group, boscalid was tested at $0,1,10,50,100,250$ and $500 \mathrm{mg} /$ litre and fluopyram at $0,0.1,0.5,1,2.5,5$ and $10 \mathrm{mg} /$ litre, on 30 isolates selected on the basis of their boscalid sensitivity, as above. None of the SDHI test isolates was the same as the AP test isolates. The phenylpyrrole fungicide, fludioxonil, was tested at $0,0.1,0.5,1,5,10$ and $50 \mathrm{mg} /$ litre and the hydroxyanilide fungicide, fenhexamid, was tested at $0,0.2,1,2.5,5,10$ and $20 \mathrm{mg} /$ litre, both against the same 30 isolates used for the AP crossresistance test.

\section{Analysis of fungicide sensitivity and interpretation of resistance}

For each $B$. cinerea isolate from the national survey, the relative growth $(\mathrm{RG})$ on the two discriminatory doses of cyprodinil and boscalid was calculated as the mean colony diameter on fungicide-amended agar divided by the mean colony diameter on the non-fungicide control, expressed as a percentage. Each isolate was classified into a sensitivity category, as follows: For cyprodinil, sensitive isolates showed RG $\leq$ $50 \%$ on $1 \mathrm{mg} /$ litre cyprodinil, low-resistance isolates showed RG $>50 \%$ on $1 \mathrm{mg} /$ litre and RG $\leq 50 \%$ on $10 \mathrm{mg} /$ litre and medium-resistance isolates had $\mathrm{RG}>50 \%$ on $10 \mathrm{mg} /$ litre. The cyprodinil sensitivity categories were similar to those used by Fernández-Ortuño et al. (2013a) for cyprodinil sensitivity of $B$. cinerea from strawberry, where sensitive isolates had a mean $\mathrm{EC}_{50}$ value of $0.6 \mathrm{mg} /$ litre (equivalent to $\mathrm{RG}=50 \%$ on $0.6 \mathrm{mg} /$ litre cyprodinil), moderately resistant isolates had mean $\mathrm{EC}_{50}$ values of 12.9 $\mathrm{mg} /$ litre (equivalent to $\mathrm{RG}=50 \%$ on $12.9 \mathrm{mg} /$

Table 1 Fungicides used as commercial formulations for sensitivity testing of Botrytis cinerea isolates collected from vineyards in Gisborne, Hawke's Bay and Marlborough.

\begin{tabular}{|c|c|c|c|c|c|}
\hline $\begin{array}{l}{ }^{1} \mathrm{FRAC} \\
\text { code }\end{array}$ & Fungicide group & $\begin{array}{l}\text { Fungicide } \\
\text { active } \\
\text { ingredient }\end{array}$ & Product & $\begin{array}{l}\text { Active } \\
\text { ingredient rate } \\
\text { in product }\end{array}$ & Batch no. \\
\hline \multirow[t]{2}{*}{9} & $\begin{array}{l}\text { Anilinopyrimidine } \\
\text { (AP) }\end{array}$ & Cyprodinil & ${ }^{2} \mathrm{Mirano}^{\circledR} \mathrm{WG}$ & $500 \mathrm{~g} / \mathrm{kg}$ & 20150615 \\
\hline & & Pyrimethanil & ${ }^{2}$ Pyrus ${ }^{\circledR} 400$ SC & $400 \mathrm{~g} / \mathrm{kg}$ & 15073500 \\
\hline \multirow[t]{2}{*}{7} & Succinate & Boscalid & ${ }^{2}$ Unistar $^{\circledR}$ & $500 \mathrm{~g} /$ litre & 15007SVT \\
\hline & $1 \mathrm{n}$ & Fluopyram & $\begin{array}{l}{ }^{3} \text { Luna }^{\circledR} \\
\text { Privilege SC }\end{array}$ & $500 \mathrm{~g} /$ litre & E221520308 \\
\hline 12 & Phenylpyrrole & Fludioxonil & ${ }^{2}$ Fludio ${ }^{\circledR} \mathrm{SC}$ & $100 \mathrm{~g} /$ litre & 02072014 \\
\hline 17 & Hydroxyanilide & Fenhexamid & ${ }^{3}$ Teldor ${ }^{\circledR}$ SL & $50 \mathrm{~g} /$ litre & EU65000249 \\
\hline
\end{tabular}

${ }^{1}$ Fungicide Resistance Action Committee

${ }^{2}$ Adria Crop Protection

${ }^{3}$ Bayer CropScience 
litre cyprodinil), and resistant isolates had mean EC50 values of $23.0 \mathrm{mg} /$ litre (equivalent to $\mathrm{RG}=50 \%$ on $23.0 \mathrm{mg} /$ litre cyprodinil). In this survey, no high-resistance category was used, because the upper discriminatory dose of 10 $\mathrm{mg} /$ litre provided no evidence as to whether any isolates had $\mathrm{EC}_{50}$ values substantially greater than $10 \mathrm{mg} /$ litre and there were relatively few isolates in the medium-resistance category, anyway.

For boscalid, sensitive isolates had RG $\leq$ $50 \%$ on $5 \mathrm{mg} /$ litre boscalid and less sensitive isolates had $\mathrm{RG}>50 \%$ on $5 \mathrm{mg} /$ litre. Isolates were classified as more or less sensitive, rather than as sensitive and resistant, because resistant $B$. cinerea isolates typically exhibit $\mathrm{EC}_{50}$ values > $100 \mathrm{mg} /$ litre (Avenot \& Michailides 2010) and therefore almost all of the isolates found in this study were more or less boscalid-sensitive.

For cross-resistance tests, $\mathrm{EC}_{50}$ values were calculated for each of the 30 isolates using linear regression of RG on $\log 10$ fungicide concentration (six concentrations) and taking the antilog of the $\log \mathrm{EC}_{50}$. The isolates were ranked by EC50 for each pair of active ingredients (cyprodinil and pyrimethanil, or boscalid and fluopyram) and correlations between the rankings were examined to determine the degree of cross-resistance between each pair. Sensitivity to fludioxonil and fenhexamid was determined by calculating $\mathrm{EC}_{50}$ values for each isolate using linear regression of RG on $\log 10$ concentration of fungicide.

\section{RESULTS}

\section{Sensitivity to cyprodinil}

Sensitivity of $B$. cinerea to cyprodinil varied widely, as shown by the frequency distributions for relative growth on 1 and $10 \mathrm{mg} /$ litre (Figure 1A). All three regions showed similar patterns, with distinctly bimodal distributions, showing small secondary peaks of low- and medium-resistance isolates (Figures 1B, 1C and 1D). The majority $(72 \%)$ of isolates were cyprodinil-sensitive, with Gisborne having the greatest percentage of sensitive isolates and Hawke's Bay the smallest percentage (Table 2). Regional differences in numbers of isolates in each resistance category were significant $(\mathrm{P}=0.015)$, reflecting the lower proportion of medium-resistance isolates in Gisborne and the greater proportion of low- and medium- resistance isolates in Hawke's Bay.

Table 2 Numbers of Botrytis cinerea isolates (percentages in brackets) from the three regions in the national survey in each of three cyprodinil sensitivity categories: 1) sensitive (relative growth $\leq 50 \%$ on $1 \mathrm{mg} /$ litre), 2) low-resistance (relative growth $>50 \%$ on $1 \mathrm{mg} /$ litre and relative growth $\leq 50 \%$ on $10 \mathrm{mg} /$ litre), and 3) medium-resistance (relative growth $>50 \%$ on $10 \mathrm{mg} /$ litre). Numbers of isolates in each resistance category differed significantly by region $\left(\chi^{2}=12.3 ; \mathrm{P}=0.015\right)$.

\begin{tabular}{lllll}
\hline Region & Sensitive & Low-resistance & Medium-resistance & Totals \\
\hline Gisborne & $168(76)$ & $41(19)$ & $11(5)$ & 220 \\
Hawke's Bay & $133(66)$ & $42(21)$ & $25(13)$ & 200 \\
Marlborough & $176(73)$ & $35(15)$ & $30(12)$ & 241 \\
\hline Totals & $477(72)$ & $118(18)$ & $66(10)$ & 661 \\
\hline
\end{tabular}

The vineyard mean RG values at each cyprodinil concentration showed that most vineyards had predominantly sensitive $B$. cinerea populations (Figure 2), with mean $\mathrm{RG} \leq 50 \%$ on $1 \mathrm{mg} /$ litre (i.e., mean $\mathrm{EC}_{50} \leq 1 \mathrm{mg} /$ litre). For the vineyards with mean RG $>50 \%$ on $1 \mathrm{mg} /$ litre cyprodinil, log-linear interpolation between RG values at 1 and $10 \mathrm{mg} /$ litre gave estimates of their mean $\mathrm{EC}_{50}$ values. These were: $2.3 \mathrm{mg} /$ litre for vineyard 1 in Gisborne, 1.0, 1.1, 1.9 and $3.9 \mathrm{mg} /$ litre for vineyards $6,4,1$ and 2 respectively in Hawke's Bay and $1.3 \mathrm{mg} /$ litre for vineyard 3 in Marlborough. These vineyards were all classified as low-resistance.

One of the two organic vineyards in each of Hawke's Bay (no. 5) and Marlborough (no. 9) 


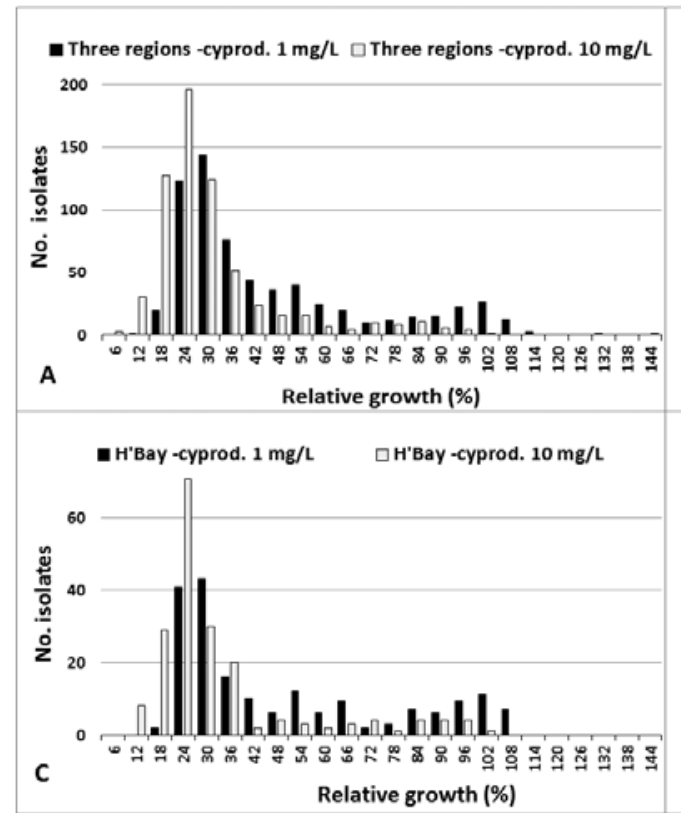

Figure 1 Frequency distributions for relative growth of the national survey of Botrytis cinerea isolates on two concentrations of cyprodinil ( $1 \mathrm{mg} /$ litre and $10 \mathrm{mg} /$ litre), for: A, three regions (661 isolates), B, Gisborne (220 isolates), C, Hawke's Bay (200 isolates) and D, Marlborough (241 isolates).

Figure 2 Mean relative growth of Botrytis cinerea isolates at two concentrations of cyprodinil (1 and $10 \mathrm{mg} /$ litre). Isolates were collected from vineyards in: A, Gisborne; B, Hawke's Bay and C, Marlborough. Vineyard numbers with asterisks were under organic management and vineyards are ranked according to relative growth on $1 \mathrm{mg} /$ litre cyprodinil.

had the most sensitive $B$. cinerea population in each of those regions (Figure 2). The other organic vineyard in each region had intermediate sensitivity. All the organic vineyards in these two regions were planted amongst non-organic vineyards. By contrast, the Gisborne organic vineyard (no. 11) was an isolated site that had received no synthetic fungicides since 1984 , about 12 years before AP fungicides became available. It had the most cyprodinil-sensitive population of all the vineyards surveyed.

- Gisborne - cyprod. $1 \mathrm{mg} / \mathrm{L}$

$\square$ Gisborne - cyprod. $10 \mathrm{mg} / \mathrm{L}$

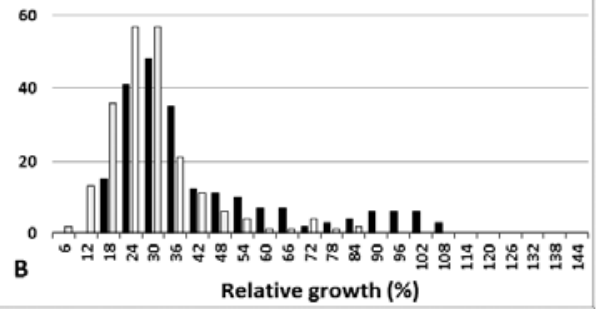

marlb. -cyprod. $1 \mathrm{mg} / \mathrm{L}$

$\square$ Marlb. -cyprod. $10 \mathrm{mg} / \mathrm{L}$
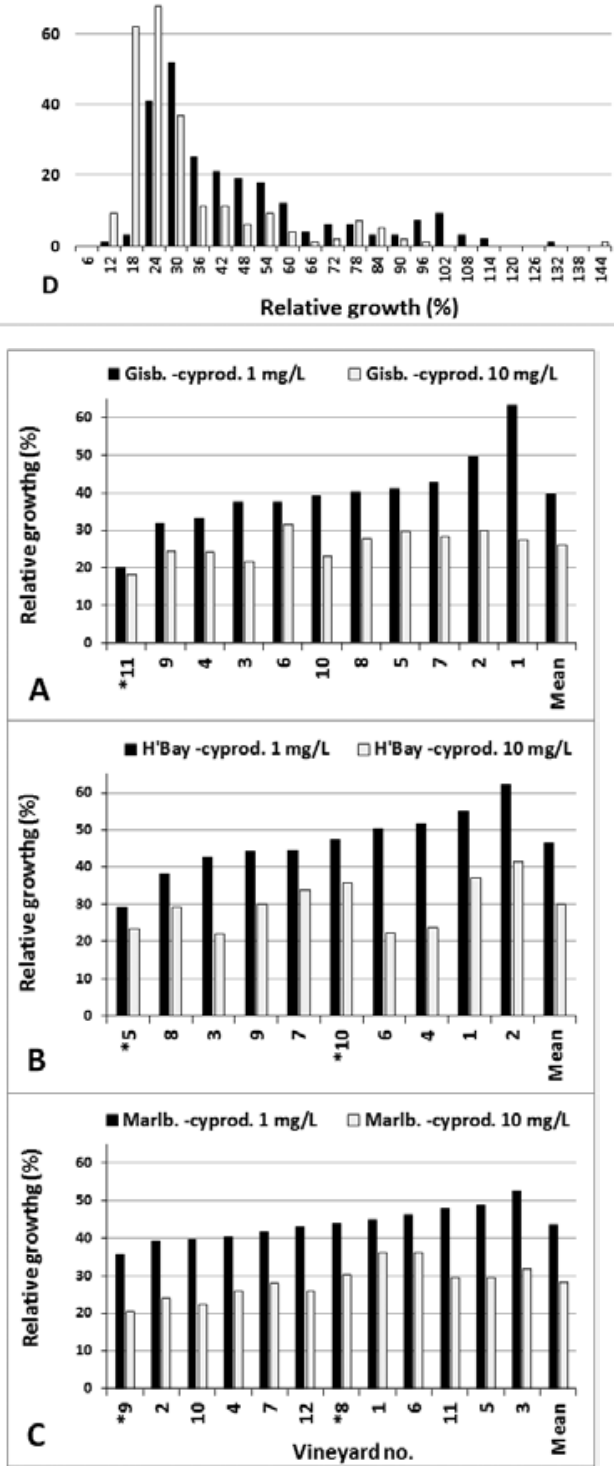


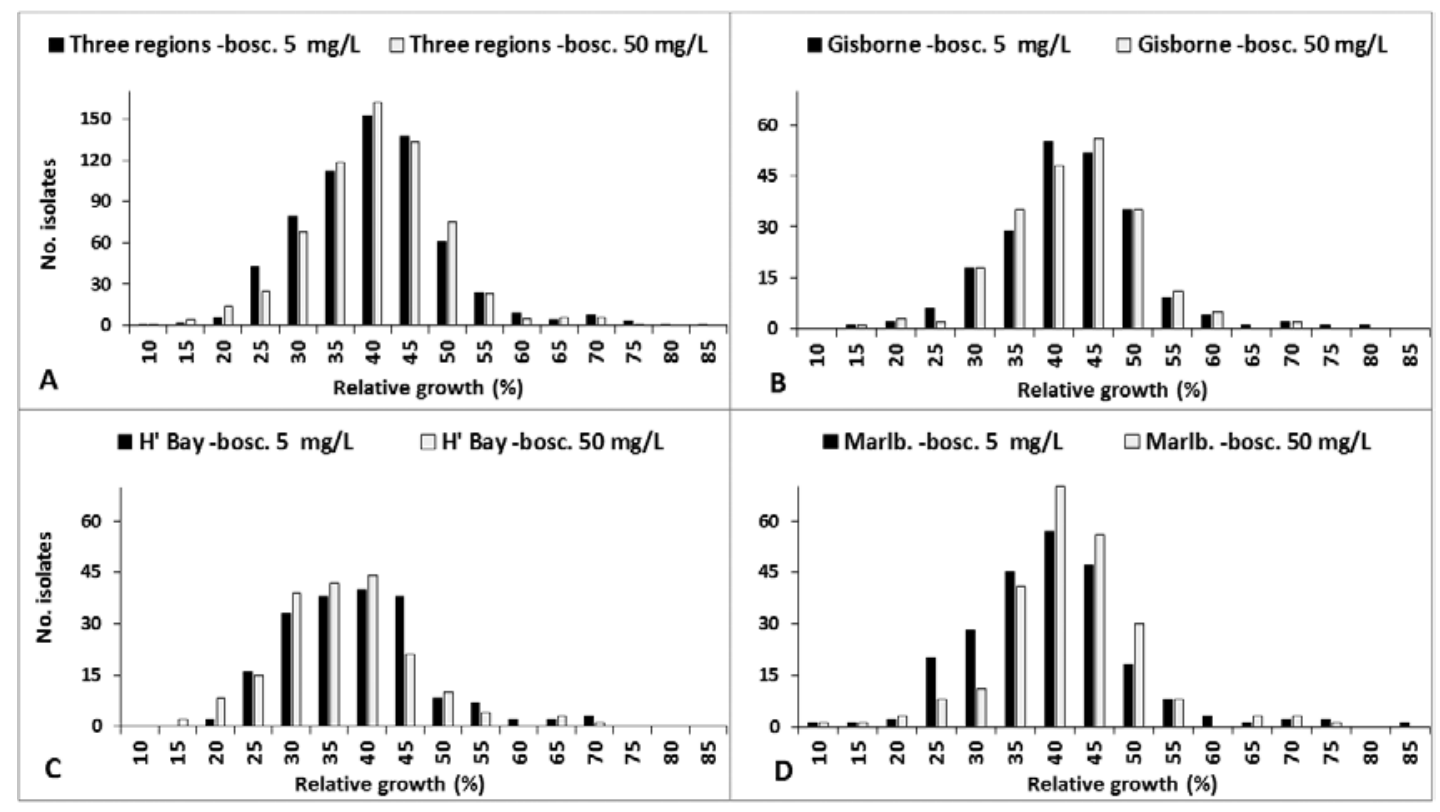

Figure 3 Frequency distributions for relative growth of the national survey of Botrytis cinerea isolates on two concentrations of boscalid ( $5 \mathrm{mg} /$ litre and $50 \mathrm{mg} / \mathrm{litre}$ ) from the national sensitivity survey, for: A, three regions (669 isolates), B, Gisborne (225 isolates), C, Hawke's Bay (200 isolates) and D, Marlborough (244 isolates).

\section{Sensitivity to boscalid}

Sensitivity of the national survey isolates to boscalid was generally normally distributed, without a strong bimodal pattern that would indicate the presence of a resistant subpopulation (Figure 3). The relative growth on 50 $\mathrm{mg} /$ litre of boscalid was as great as on $5 \mathrm{mg} /$ litre, indicating that a higher upper discriminatory dose of boscalid (e.g. $100 \mathrm{mg} /$ litre) would have allowed better definition of sensitivity. Nevertheless, most isolates (91\%) were inhibited at $5 \mathrm{mg} /$ litre $\left(\mathrm{EC}_{50} \leq 5 \mathrm{mg} /\right.$ litre $)$, indicating high sensitivity of the $B$. cinerea population nationally (Table 3). There were no significant regional differences in numbers of isolates in each sensitivity category $(\mathrm{P}=0.408)$. The vineyard means of RG showed that mean $\mathrm{EC}_{50}$ values for boscalid were all $<5 \mathrm{mg} /$ litre (data not shown). The organic vineyards showed a similar range of boscalid sensitivity to the non-organic vineyards, including the geographically isolated Gisborne organic vineyard, no. 11 (data not shown).
Table 3 Numbers of Botrytis cinerea isolates (percentages in brackets) from the three regions in the national survey in two boscalid sensitivity categories: 1 ) sensitive (relative growth $\leq 50 \%$ on $5 \mathrm{mg} /$ litre) and 2) less sensitive (relative growth $>50 \%$ on $5 \mathrm{mg} /$ litre. Numbers of isolates in each sensitivity category did not differ significantly by region $\left(\chi^{2}=1.79 ; \mathrm{P}=0.408\right)$.

\begin{tabular}{llll}
\hline Region & Sensitive & Less sensitive & Totals \\
\hline Gisborne & $201(89)$ & $24(11)$ & 225 \\
Hawke's Bay & $186(93)$ & $14(7)$ & 200 \\
Marlborough & $223(91)$ & $21(9)$ & 244 \\
\hline Totals & $610(91)$ & $59(9)$ & 669 \\
\hline
\end{tabular}

Fungicide use and $B$. cinerea sensitivity in the surveyed vineyards

The fungicide-use questionnaire showed that, in the last five years (2011-12 to 2015-16), the number of applications of at-risk botryticides per season averaged 3.2 in Gisborne, 2.2 in Hawke's Bay and 2.1 in Marlborough. In the previous 
10 seasons, fewer had been used per season in Gisborne (2.7) and slightly more in Hawke's Bay (2.7) and Marlborough (2.6).

For the AP, cyprodinil (mixed with fludioxonil), the number of applications per season averaged 1.3 in Gisborne, 0.7 in Hawke's Bay and 1.1 in Marlborough. For pyrimethanil, the averages were 0.2 in Gisborne, 0.1 in Hawke's Bay and 0.2 in Marlborough. Compared with the previous 10 years, the total number of AP applications had stayed about the same in Gisborne and decreased by about half in Hawke's Bay and Marlborough. In all regions, use of pyrimethanil had decreased compared with that of cyprodinil. Analysis of cyprodinil sensitivity in relation to AP fungicide use (including organic) found no significant relationship between the mean relative growth values at 1 or $10 \mathrm{mg} /$ litre for the individual vineyards and the corresponding number of AP fungicide applications per season in those vineyards.

Use of SDHI fungicides was negligible, with an average over the last five seasons of $<0.1$ application per season of boscalid (mixed with pyraclostrobin) in Gisborne and Marlborough and none in Hawke's
Bay. No SDHI fungicides were used in the previous 10 seasons. No fluopyram use was recorded. The number of applications of fluazinam in the last five seasons was 0.7-1.4 per season, with more use in Gisborne and Hawke's Bay than in Marlborough. Fenhexamid use was $<0.2$ applications per season, which was less than during the previous 10 seasons (0.3-0.6 applications per season). A small amount of iprodione was used over the previous 10 seasons $(<0.2$ applications per season $)$ and none was used in the last five seasons. No carbendazim use was recorded. No correlations were found between B. cinerea sensitivity and numbers of applications of boscalid or fenhexamid.

\section{Cross-resistance}

For the 30 national survey isolates that were used in the AP cross resistance study, the ranking of individual $\mathrm{EC}_{50}$ values on cyprodinil and pyrimethanil was similar, indicating that these two AP fungicides have a high degree of crossresistance (Figure 4A). For the 15 least cyprodinilresistant isolates, the $\mathrm{EC}_{50}$ values on cyprodinil $(1.1 \mathrm{mg} /$ litre $)$ and pyrimethanil $(1.9 \mathrm{mg} /$ litre $)$ were

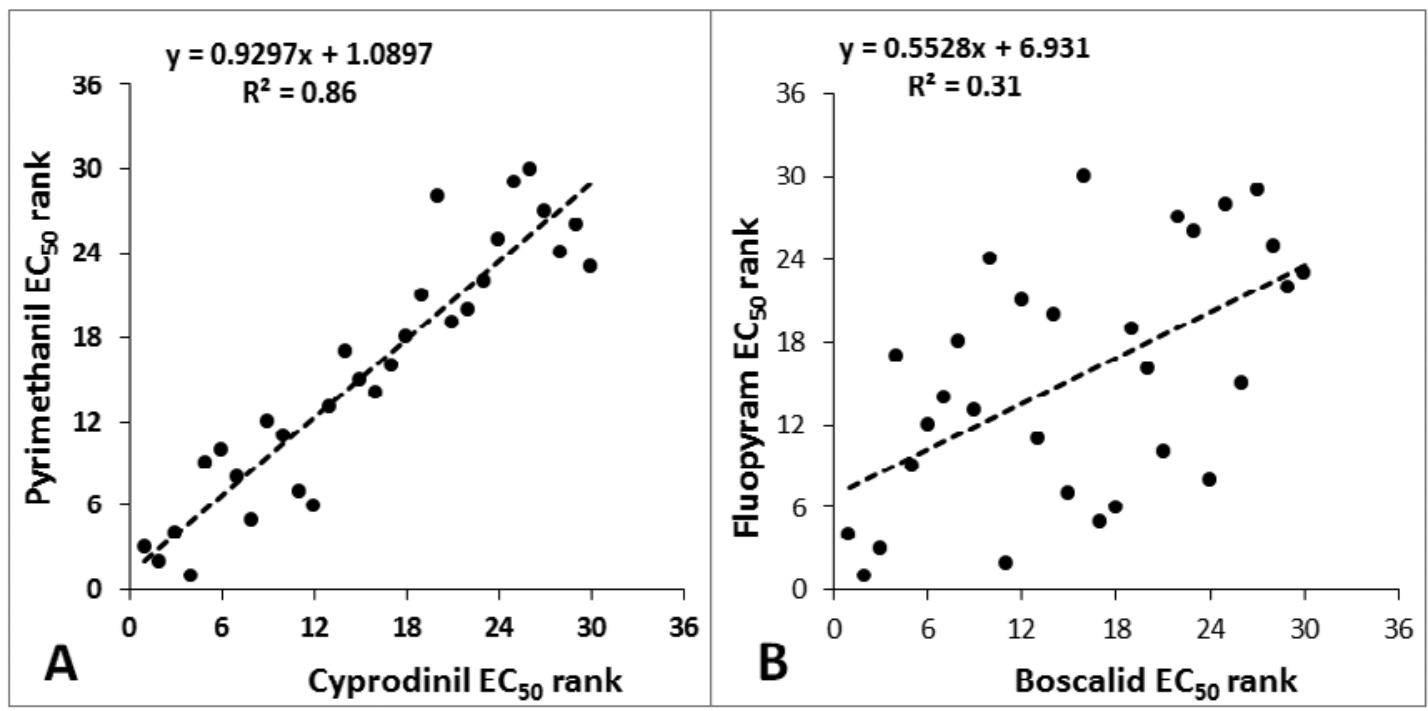

Figure $4 \mathrm{~A}$ : Association between the $\mathrm{EC}_{50}$ rankings on cyprodinil and pyrimethanil for 30 Botrytis cinerea isolates used in the anilinopyrimidine cross-resistance study $(\mathrm{P}<0.001)$. B: Association between the $\mathrm{EC}_{50}$ rankings on boscalid and fluopyram for 30 Botrytis cinerea isolates used in the succinate dehydrogenase inhibitor cross-resistance study $(\mathrm{P}>0.05)$. 
similar, showing that both fungicides gave similar inhibition of the sensitive isolates. By contrast, for the 15 most cyprodinil-resistant isolates, there was much less inhibition by pyrimethanil (mean $\mathrm{EC}_{50}, 28,788 \mathrm{mg} /$ litre) than by cyprodinil (mean $\left.\mathrm{EC}_{50}, 115 \mathrm{mg} / \mathrm{litre}\right)$. If these in vitro results were to translate to field performance, then it suggests that pyrimethanil may lose field efficacy to a greater extent in the presence of resistant $B$. cinerea strains than cyprodinil, although the performance of both fungicides would most likely be compromised.

For the SDHI cross-resistance study using boscalid and fluopyram, the $\mathrm{EC}_{50}$ values for the 15 least boscalid-resistant isolates were similar $(4.3 \mathrm{mg} /$ litre for boscalid and $2.8 \mathrm{mg} /$ litre for fluopyram). For the 15 most boscalid-resistant isolates, there was much less inhibition by boscalid (mean $\mathrm{EC}_{50}$, $843 \mathrm{mg} /$ litre), than by fluopyram (mean $\mathrm{EC}_{50}$, $9.9 \mathrm{mg} /$ litre), showing that fluopyram was able to inhibit the most boscalid-resistant isolates from the national survey to a much greater extent than boscalid. In the case of these two SDHIs, there was a low degree of cross-resistance compared with that in the two APs, as shown by the lower $R^{2}$ value $(0.31)$ for the rankings of each isolate's $\mathrm{EC}_{50}$ values on boscalid and fluopyram (Figure 4B).

\section{Sensitivity to fludioxonil and fenhexamid}

Sensitivity to fludioxonil was very high and the lowest concentration ( $0.1 \mathrm{mg} /$ litre $)$ inhibited RG by $>50 \%$ for all except one isolate. At concentrations > $5 \mathrm{mg} /$ litre, all isolates were completely inhibited. The mean (extrapolated) $\mathrm{EC}_{50}$ value of fludioxonil for the AP-sensitive isolates tested was $0.018 \mathrm{mg} / \mathrm{litre}$, and for the AP-resistant isolates was $0.009 \mathrm{mg} / \mathrm{litre}$. An additional fludioxonil concentration $<0.1 \mathrm{mg} /$ litre, would have given better definition of fludioxonil $\mathrm{EC}_{50}$ values. The mean fenhexamid $\mathrm{EC}_{50}$ value for the cyprodinil-sensitive isolates was $0.49 \mathrm{mg} /$ litre and for the cyprodinil-resistant isolates was $0.76 \mathrm{mg} /$ litre, indicating little variation in sensitivity and little association with AP resistance.

\section{DISCUSSION}

This study has shown that New Zealand B. cinerea populations are predominantly sensitive to AP fungicides (cyprodinil $\mathrm{EC}_{50}$ values $<1 \mathrm{mg} /$ litre), although a low-resistance sub-population exists throughout the regions, comprising $18 \%$ of isolates, nationally. The degree of resistance of this subpopulation (cyprodinil $\mathrm{EC}_{50}$ values between 1 and $10 \mathrm{mg} /$ litre) is unlikely to be affecting botrytis bunch rot control at present. However, the additional medium-resistance sub-population (cyprodinil $\mathrm{EC}_{50}$ values $>10 \mathrm{mg} /$ litre), comprising $10 \%$ of isolates, is of concern because the frequency of such isolates could increase with continued AP use and would be likely to compromise disease control (Fernández-Ortuño et al. 2013a). The high crossresistance between cyprodinil and pyrimethanil suggests that resistance will develop similarly to both these AP fungicides. The bimodal distribution of sensitivity to cyprodinil suggests that disruptive selection of genotypes with one or a few resistance genes is occurring (De Miccolis Angelini et al.2015). Although single gene mutation has been proposed for AP resistance (Hilber \& Hilber-Bodmer 1998), the molecular mode of action of APs has not yet been resolved and resistance gene loci have not been mapped (Hahn 2014). It is not known whether the more resistant strains found in this study could survive in the absence of AP fungicide selection and, therefore, whether the resistance frequency would decrease if AP fungicide use were reduced.

The comparison of cyprodinil sensitivity among the organic blocks in this study suggests that resistant $B$. cinerea strains may migrate readily between organic and nonorganic blocks that are in fairly close proximity (e.g. $<5 \mathrm{~km}$ apart). This is shown by the contrast between the similar cyprodinil sensitivity in the Hawke's Bay and Marlborough organic vineyards and nearby non-organic vineyards, compared with the greater cyprodinil sensitivity of the geographically isolated Gisborne organic vineyard compared with the Gisborne nonorganic vineyards. This suggests resistant strains have moved between vineyards within Hawke's Bay and Marlborough.

The lack of any relationship between history of AP fungicide use and sensitivity to AP fungicides in the individual vineyards was not surprising, as this is a common outcome for this type of study. The 1985 
New Zealand survey of $B$. cinerea benzimidazole resistance (Beever et al. 1989) found no correlation between benzimidazole use and resistance frequency in individual vineyards. Other more recent New Zealand studies also found no correlation at the individual vineyard or orchard level between fungicide sensitivity and spray diary records for Erysiphe necator in grapes (Beresford et al 2016), or for Venturia inaequalis in apples (Beresford et al. 2013). There could be several reasons for a lack of correlation between fungicide use and pathogen sensitivity, including: 1) fungicide usage differing little between vineyards over the time frame relevant to resistance selection, 2) migration of pathogen strains between vineyards and 3) sample sizes too small to quantify small differences in sensitivity accurately between individual vineyards.

Sensitivity to boscalid was high in this study, which was to be expected because there has so far been little SDHI use in New Zealand vineyards. Baseline sensitivity values for $B$. cinerea to boscalid and fluopyram are provided by the mean $\mathrm{EC}_{50}$ values for the boscalid-sensitive isolates in the cross-resistance study. These were $4.3 \mathrm{mg} /$ litre for boscalid and $2.8 \mathrm{mg} /$ litre for fluopyram and these will provide a baseline for comparison for future SDHI sensitivity monitoring. The low cross-resistance of $B$. cinerea to boscalid and fluopyram was expected since cross-resistance patterns among SDHIs are known to be complex and involve many mutations with varying effects (Sierotzki \& Scalliet 2013, Amiri et al. 2014).

Fludioxonil is a single-site inhibitor that interferes with osmoregulation Hahn (2014). Resistance in $B$. cinerea has only recently been reported from strawberries in the USA (Fernández-Ortuño et al. 2013b, Li et al. 2014) and the lack of fludioxonil resistance found in this study was to be expected since it has not been reported from grapevines overseas. Fenhexamid, a Class III sterol biosynthesis inhibitor, has been in use in New Zealand since about 2001 and resistance has been reported in grapevines in France (Billard et al. 2012) and strawberries in the USA (Grabke et al. 2013), where high usage has occurred. The spray diary analysis showed that fenhexamid use in New Zealand is very low, which probably accounts for the high fenhexamid sensitivity found in this study.

This survey has shown that AP resistance is not yet a major problem in New Zealand vineyards, although a shift in sensitivity towards resistance may be occurring, especially in Hawke's Bay. Given that fungicide sensitivity is spatially variable, it is possible that some vineyards may already have a frequency of AP-resistant strains that is compromising control of botrytis bunch rot. The indication from spray diary analysis that AP use has decreased in the last five seasons is encouraging, particularly for Hawke's Bay where the greatest frequency of resistant isolates was found. It will be important for the New Zealand wine and agrochemical industries to manage a reduction in reliance on AP fungicides for B. cinerea control over the next 5 years.

\section{ACKNOWLEDGEMENTS}

This research was funded by New Zealand Winegrowers, Adama NZ Ltd, Adria Crop Protection, BASF Crop Protection, Bayer CropScience, Etec, Fruitfed/PGG Wrightson, Orion Crop Protection, Syngenta Crop Protection, Tasman Crop Protection, The NZ Horticentre Trust and Zelam. Thanks are due to the participating vineyard managers who gave access to vineyards for Botrytis cinerea sampling and supplied spray diaries and to Adria Crop Protection and Bayer CropScience for supplying the fungicide products that were tested.

\section{REFERENCES}

Amiri A, Heath S M, Peres NA 2014. Resistance to fluopyram, fluxapyroxad, and penthiopyrad in Botrytis cinerea from strawberry. Plant Disease 98:532-539.

Avenot H, Michailides TJ 2010. Progress in understanding molecular mechanisms and evolution to succinate dehydrogenase inhibiting (SDHI) fungicides in phytopathogenic fungi. Crop Protection 29: 643-651.

Beever RE, Laracy EP, Pak HA 1989. Strains of Botrytis cinerea resistant to dicarboximide and benzimidazole fungicides in New Zealand vineyards. Plant Pathology 38: 427-437. 
Beresford RM 2011. Succinate dehydrogenase inhibitor fungicide resistance prevention strategy. http://resistance.nzpps.org/index. php? $\mathrm{p}=$ fungicides/sdhi. Accessed 8 December 2016.

Beresford R, Manktelow M, van der Zijpp S, Follas G, Moore M Harris G 2014. Resistance management guideline for anilinopyrimidine (AP) [Group 9] fungicides used against botrytis bunch rot (Botrytis cinerea) in wine grapes in New Zealand. http://resistance. nzpps.org/index.php? $\mathrm{p}=$ fungicides/ap_in_ grapes. Accessed 8 December 2016.

Beresford R, Pak H, Manktelow D, Follas G, Hagerty G 1999. Strategies to avoid resistance development to anilopyrimidine fungicides in New Zealand. New Zealand Plant Protection 52: 176-178.

Beresford RM, Wright PJ, Wood PN, Agnew RH 2016. Sensitivity of grapevine powdery mildew (Erysiphe necator) to demethylation inhibitor and quinone outside inhibitor fungicides in New Zealand. New Zealand Plant Protection 69: 1-10.

Beresford RM, Wright PJ, Wood PN, Park NM, Larsen NJ, Fisher BM 2013. Resistance of Venturia inaequalis to demethylation inhibitor and dodine fungicides in four New Zealand apple growing regions. New Zealand Plant Protection 66:274-283.

Billard A, Fillinger S, Leroux P, Lachaise H, Beffa R, Debieu D 2012. Strong resistance to the fungicide fenhexamid entails a fitness cost in Botrytis cinerea, as shown by comparisons of isogenic strains. Pest Management Science 68: 684-691. DOI 10.1002/ps.2312.

De Miccolis Angelini RM, Pollastro S, Faretra F 2015. Genetics of fungicide resistance. In: Fungicide Resistance in Plant Pathogens: Principles and a Guide to Practical management. Edited by Ishii $\mathrm{H}$, Hollomon DW. Springer $489 \mathrm{p}$.

Fernández-Ortuño D, Chen F, Schnabel G 2013a. Resistance to cyprodinil and lack of fludioxonil resistance in Botrytis cinerea isolates from strawberry in North and South Carolina. Plant Disease. 97: 81-85.
Fernández-Ortuño D, Bryson P-K, Grabke A, Schnabel G 2013b. First Report of fludioxonil resistance in Botrytis cinerea from a strawberry field in Virginia. Plant Disease 97: 848.

FRAC 2015. Succinate Dehydrogenase Inhibitor (SDHI) Working Group 9th Meeting on December 2, 2015. http://www.frac.info/ docs/default-source/sdhi-wg/sdhi-meetingminutes/minutes-of-the-2015-sdhi-meetingrecommendations-for-2016.pdf? status $=$ Tem p\&sfvrsn $=0.6039098515175283$. Accessed 26 March 2017.

Grabke A, Fernández-Ortuño D, Schnabel G 2013. Fenhexamid resistance in Botrytis cinerea from strawberry fields in the Carolinas is associated with four target gene mutations. Plant Disease 97: 271-276.

Hahn M 2014. The rising threat of fungicide resistance in plant pathogenic fungi: Botrytis as a case study. Journal of Chemical Biology 7: 133-141.

Hilber UW, Hilber-Bodmer M 1998. Genetic basis and monitoring of resistance of Botryotinia fuckeliana to anilinopyrimidines. Plant Disease 82: 496-500.

Li X, Fernández-Ortuño D, Grabke A, Schnabel G 2014. Resistance to fludioxonil in Botrytis cinerea isolates from blackberry and strawberry. Phytopathology 104: 724-732.

Milling R, Richardson CJ 1995. Mode of action of the anilino-pyrimidine fungicide pyrimethanil. 2. Effects on enzyme secretion in Botrytis cinerea. Pest Managament Science 45: 43-48.

Sierotzki H, Scalliet G 2013. A review of current knowledge of resistance aspects for the next-generation succinate dehydrogenase inhibitor fungicides. Phytopathology 103: 880-887.

Walker A-S, Micoud A, R'emuson F, Grosman, Gredta M, Lerouxa P 2013. French vineyards provide information that opens ways for effective resistance management of Botrytis cinerea (grey mould). Pest Management Science 69: 667-678. Wileyonlinelibrary.com. DOI 10.1002/ps.3506. 